\title{
Ether-functionalized Sulfonium Ionic Liquid and its Binary Mixtures With Acetonitrile as Electrolyte for Electrochemical Double Layer Capacitors: a Molecular Dynamics Study
}

\author{
Abner Massari Sampaio and Leonardo José Amaral Siqueira* \\ Laboratório de Materiais Híbridos, Departamento de Química, Instituto de Ciências Ambientais, \\ Químicas e Farmacêuticas, Universidade Federal de São Paulo, Rua São Nicolau, 210 \\ Diadema-SP-CEP 09913-030 - Brazil. \\ E-mail: ljasiqueira@unifesp.br
}

\begin{abstract}
Ether-functionalized sulfonium ionic liquids have been investigated as promising electrolytes in electrochemical storage energy devices due to their wide electrochemical window, high ionic conductivity and low viscosity. In spite of that, the viscosity of neat ionic liquids is still high for supercapacitor applications. Here we have used atomistic molecular dynamics simulations to describe transport properties, structure and supercapacitor performance of (2-methoxy-ethyl)-ethyl-methylsulfonium bis(trifluoromethanesulfonyl)imide $\left[\mathrm{S}_{12 \mathrm{G1}}\right]\left[\mathrm{NTf}_{2}\right]$ and its mixtures with acetonitrile (ACN). The viscosity and ionic conductivity of neat ionic liquid are in quite good agreement with the experimental results in a wide range of temperature. The addition of ACN decreases viscosity and, consequently, increases ionic conductivity and diffusion coefficients. Typical alternated layers of ions close to the electrodes surfaces are observed in supercapacitor built with $\left[\mathrm{S}_{12 \mathrm{G1}}\right]\left[\mathrm{NTf}_{2}\right]$ when is applied high voltage, $\Delta \Psi=3.0 \mathrm{~V}$. Sharp layers of solvent adsorbed on the surface of electrodes are observed in the mixtures containing ACN. The charge accumulated on the electrodes is barely affected by the amount of ACN, which imply in similar performance in terms of ca-
\end{abstract}

pacitance. However, the charging times follow the viscosities of the electrolytes, that is, the electrolytes with high content of $\mathrm{ACN}$ have higher power performance. At low voltage, the rearrangements of ions close to electrodes responsible to the charge accumulation is very low in neat $\left[\mathrm{S}_{12 \mathrm{G} 1}\right]\left[\mathrm{NTf}_{2}\right]$. The sharp layer of $\mathrm{ACN}$ makes this rearrangement easier, but it acts as a barrier to ion exchange at higher voltages, which increase the charging time. Charging of the supercapacitors is dependent of ion exchange and counter-ion adsorption at $\Delta \Psi=$ $3.0 \mathrm{~V}$.

\section{Introduction}

Over the past few decades, a class of ionic systems with melting point below $100{ }^{\circ} \mathrm{C}$ have received great attention from the academic and industry community. Known as room temperature ionic liquids or simply ionic liquids, this class of material gather a lot of interesting properties, such as high electrochemical stability, low vapor pressure, and high possibility to tune physical chemistry properties by combining different cations and/or anions, beyond the functionalization of alkyl side chains. ${ }^{1-6}$ This great versatility makes this class of material interesting for a large variety of applica- 
tions, for instance, solvent/catalist for organic reactions, ${ }^{7-9}$ gas absorber, ${ }^{10-13}$ lubricants, ${ }^{14}$ and electrolytes. ${ }^{15-20}$ Regarding their ability as electrolyte, several class of ionic liquids have been investigated as promising materials for battery and/or electric double-layer capacitors (EDLC) or simply supercapacitors. ${ }^{21-31}$ Among many class of ionic liquids investigated as electrolytes for supercapacitors, the ones formed with sulfonium cations have received great attention due to their high ionic conductivity, low viscosity and relative high electrochemical stability. ${ }^{32-36}$ Besides these interesting properties, sulfonium-based ionic liquids are small cations, which would allow better performance as electrolyte for supercapacitors, providing electrochemical devices with higher energy density. ${ }^{33,36}$

Although ionic liquids have wider electrochemical window than water and many organic solvents (acetonitrile, adiponitrile, ethylenecarbonate), they still have high viscosity and low ionic conductivity for electrochemical applications. ${ }^{31}$ The functionalization of cations with ether function usually provides ionic liquids with lower viscosity (higher diffusion coefficients and ionic conductivities) than their cations analogues containing only alkyl chains. ${ }^{36-38}$ Beyond the cation modification, the addition of organic solvents such as acetonitrile yields electrolytes with lower viscosity (higher ionic conductivity) than the neat corresponding ionic liquids. ${ }^{5,39,40}$ The enhancement of the transport properties of the electrolytes improves power density of electrochemical double layer capacitor (supercapacitor), but their energy density may be diminished due to narrower electrochemical window of the solvent. In fact, previous experimental studies have shown that solvating ionic liquids with acetonitrile and propylene carbonate, the power performance can be remarkably improved, up to one order of magnitude, whereas the energy density can decrease up to $30 \%$ of that observed for respective neat ionic liquid. ${ }^{25,41-43}$

Molecular dynamics (MD) simulations studies on the solvation of many class of ionic liquids with organic solvents have been per- formed. ${ }^{39,44-47}$ The main conclusion is that increasing the amount of the organic solvent the ionic liquids diffusivity also increases, following the experimental trend. Chaban et al. ${ }^{39}$ systematicaly investigated a serie of $\mathrm{N}$-alkyl-N-methyl-imidazolium tetrafluoroborate ionic liquids mixtured with acetonitrile $(\mathrm{ACN})$. They showed that the addition of $\mathrm{ACN}$ increases the ionic conductivity more than 50 times for the long-tailed ionic liquids and around 10 times for those with shorter chains. The maxima of ionic condutivities were found around 20\% IL mole fraction. More recently, Thompson et al. ${ }^{48}$ investigated mixtures of 1-butyl-3-ethyl-imidazolium bis(trifluoro-methane-sulfonyl)imide ionic liquid with many organic solvents and found a monotonical increase of diffusion coefficients of the ions with the addition of solvents. Expressing the mixture composition by mass fraction of ionic liquids, these authors showed that the maxima of ionic conductivities estimated by Nersnt-Einstein relation are found at intermediate concentrations, that is, between 0.4 and 0.6 mass fraction of ionic liquid. Among the investigated organic solvents, $\mathrm{ACN}$ is the solvent capable to allow the largest increase in ionic conductivity.

Many computer simulations at atomistic level of supercapacitors have been accomplished with constant charge (CCM $)^{49-51}$ (less expensive computationally) and constant potential models (CPM). ${ }^{52-55}$ As pointed out by Merlet et al. ${ }^{53}$ the structure of ion at the surface of planar electrodes and also capacitance are fairly described by constant charge models. However, dynamics properties are remarkable different. For instance, sudden application of voltage to the electrode using $\mathrm{CPM}$, the increase in temperature follows Ohm's law, while in CCM unphysical temperatures arise in the system. ${ }^{53}$ Additionally, there are some computational studies devoted to the investigation of charging dynamics of supercapacitors built with porous electrodes, ${ }^{56-58}$ whereas for planar electrodes it is more rare. ${ }^{54}$ Therefore, considering the promising good performance as supercapacitor electrolytes of ether-functionalized 
sulfonium-based ionic liquids, for instance, the (2-methoxy-ethyl)-ethyl-methylsulfonium bis(trifluoromethanesulfonyl)imide $\left(\left[\mathrm{S}_{12 \mathrm{G} 1}\right]\left[\mathrm{NTf}_{2}\right]\right)$ ionic liquid, we investigated by means of molecular dynamics simulations transport properties, structure and supercapacitor performance using CPM of $\left[\mathrm{S}_{12 \mathrm{G} 1}\right]\left[\mathrm{NTf}_{2}\right]$ and its mixture with $\mathrm{ACN}$.

\section{Computational Details}

\subsection{Bulk Simulations}

The electrolytes were simulated in cubic boxes generated with PACKMOL package. ${ }^{59}$ The structures of the ions and $\mathrm{ACN}$ are depicted in Figure 1a.

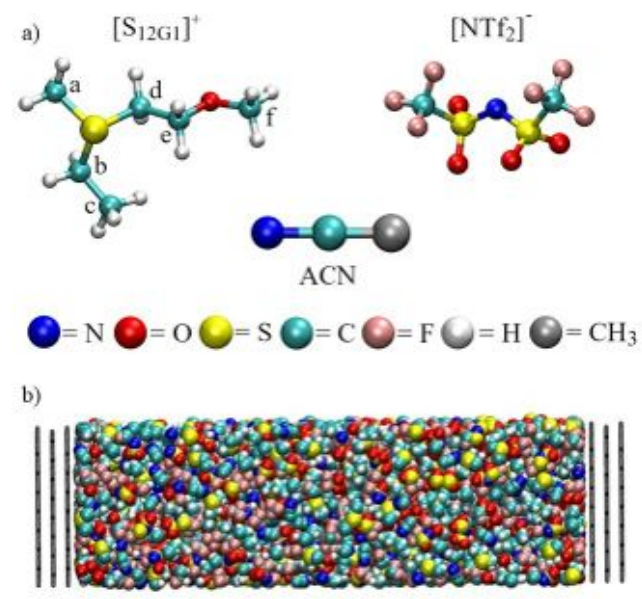

Figure 1: a) Molecular structures of the investigated systems, $\left[\mathrm{S}_{12 G 1}\right]^{+}$on the left, $\left[\mathrm{NTf}_{2}\right]^{-}$on the right, and $\mathrm{ACN}$ in the bottom middle. b) Snapshot of the simulation Cell. The graphite walls are represented in grey.

All the simulations were conducted with a non-polarizable force field with scaled-charges (scaling factor 0.8). The scaled-charge approach has been previously used to describe with excellent accuracy mass density, transport properties and enthalpy of vaporization. ${ }^{60-65}$ The partial charges of $\left[\mathrm{S}_{12 \mathrm{G} 1}\right]^{+}$cation were derived from the electrostatic potential (CHELPG) ${ }^{66}$ obtained from DFT calculations using the B3LYP functional and Gaussian basis set $6-311++G(d, p)$ in Gaussian09 package. ${ }^{67}$
Lennard-Jones parameters of the intermolecular potential of $\left[\mathrm{S}_{12 \mathrm{G} 1}\right]^{+}$cation were taken from OPLS/AA force field. ${ }^{68,69}$ The $\mathrm{NTf}_{2}$ anions and ACN were simulated with model used in previous simulations. ${ }^{13,24,49,55,70,71}$ All the parameters used in the simulations, the number of ionic pairs and acetonitrile molecules used in each system are available in Tables S1 to $\mathrm{S} 7$ of the supporting information. The $x_{A C N}$ $=0.5$ and 0.88 correspond to a $3.0 \mathrm{M}$ and a $1.5 \mathrm{M}$ solution of ionic liquid and acetonitrile.

The neat ionic liquid were equilibrated in NPT ensemble followed by a production run conducted for $40 \mathrm{~ns}$ in NVT ensemble at 400, $375,350,325$ and $300 \mathrm{~K}$. At low temperatures ( 300 up to $350 \mathrm{~K}$ ) the ionic liquids were equilibrated for $20 \mathrm{~ns}$, whereas at 375 and $400 \mathrm{~K}$ the equilibrations last for $10 \mathrm{~ns}$. The binary mixtures with ACN were simulated at $300 \mathrm{~K}$. Temperatures were controlled by V-rescale thermostat $(\tau=1 \mathrm{ps})^{72}$ and pressure by ParrinelloRahman barostat ( $\tau=3 \mathrm{ps}) .{ }^{73}$ Lennard-Jones and real space coulombic interactions were cut off at $1.5 \mathrm{~nm}$. Coulomb long-range interactions were dealt with Particle Mesh Ewald $(\mathrm{PME})^{74}$ method with an interpolation order of 6 and $0.08 \mathrm{~nm}$ grid spacing. The leapfrog algorithm was used to integrate the equation of motion with time step of $2 \mathrm{fs}$, constraining the $\mathrm{C}-\mathrm{H}$ bonds with LINCS $^{75}$ algorithm. TRAVIS software package ${ }^{76}$ was used to calculate spatial distribution functions. GROMACS suite program was used to perform the MD simulations. ${ }^{77-80}$

\subsection{Interfacial Simulations}

LAMMPS package was used to perform the moleuclar dynamics simulation of the $\left[\mathrm{S}_{12 \mathrm{G} 1}\right]\left[\mathrm{NTf}_{2}\right]$ ionic liquid and its mixtures with acetonitrile placed in between two graphite electordes with planar geometry as depicted in Figure $1 \mathrm{~b}$. The initial configurations were also generated with PACKMOL package ${ }^{59}$ and the distance of the two graphite electrodes was set up to provide the bulk density between the electrodes.

The simulations were conducted using the constant potential method implemented on 
LAMMPS code, ${ }^{81-83}$ which allow the charges of the electrode carbon atoms to fluctuate in response to the interaction with the electrolyte atoms. This method ensures an realistic description of the surface polarization over the entire simulation time. A vacuum space was added outside the box along the $z$-axis and the Yeh-Berkowitz corrections for the slab geometry was applied to proper description of periodic conditions.

Several applied voltages have been used in the simulations $(\Psi=0.0,0.5,1.0,1.5,2.0,2.5$, $3.0 \mathrm{~V})$. The initial configuration for every applied voltage was the same, in order to evaluate the charge evolution as a function of the voltage. The simulations were performed in the NVT ensemble with a timestep of $2 \mathrm{fs}$ at $300 \mathrm{~K}$ for at least $3 \mathrm{~ns}$, which has been long enough to reach the maximum charge accumulated on the electrodes.

\subsection{Transport Properties Calcula- tions}

The diffusion coefficient was calculated by the Einstein relation, fitting a straight line in the linear regime of mean square displacement: ${ }^{84}$

$$
D_{\alpha}=\lim _{t \rightarrow 0} \frac{1}{6 t}\left\langle\left|\boldsymbol{r}_{\boldsymbol{i}}(t)-\boldsymbol{r}_{\boldsymbol{i}}(0)\right|^{2}\right\rangle
$$

where $D_{\alpha}$ is the diffusion coeficient, $t$ is time and $\mathbf{r}_{i}(t)$ is the position of the specie in the time $t$.

The viscosity was calculated by the integration of the time correlation function of the pressure tensor: 84

$$
\eta=\frac{V}{k_{B} T} \int_{0}^{\alpha}\left\langle P_{\alpha \beta}(t) P_{\alpha \beta}(\tau)\right\rangle d \tau
$$

where $k_{B}$ is the Boltzmann constant, $P_{\alpha \beta}$ is one of the elements outside the principal diagonal of the pressure tensor, and $\alpha \beta=x y, x z, y z$.

The ionic conductivity was calculated considering the collective version of the mean square displacement following the equation: ${ }^{84}$

$$
\sigma=\frac{e^{2}}{6 k_{B} T V} \lim _{t \rightarrow 0} \sum_{i j}^{N} q_{i} q_{j}\left\langle\left[\boldsymbol{r}_{\boldsymbol{i}}(t)-\boldsymbol{r}_{\boldsymbol{i}}(0)\right] \cdot\left[\boldsymbol{r}_{\boldsymbol{j}}(t)-\boldsymbol{r}_{j}(0)\right]\right\rangle
$$

where $e$ is the elementary charge, $k_{B}$ is the Boltzmann constant, $T$ is the temperature in Kelvin, $V$ in the volume of the simulation box and $q_{i}$ is the formal charge of the ions.

The ionic conductivity was also estimated by the Nernst-Einstein equation: ${ }^{85}$

$$
\sigma^{N E}=\frac{e^{2}}{k_{B} T}\left(\rho_{-} q_{-}^{2} D_{-}+\rho_{+} q_{+}^{2} D_{+}\right)
$$

where $k_{B}$ is the Boltzmann constant, $\rho$ is the number density, $q$ is the charge of the ions, and $D$ is the diffusion coefficient of each specie.

\subsection{Electrical Properties Calcula- tions}

The differential capacitance of each electrode depends on the surface charge $\left( \pm \rho_{s}\right)$ of each electrode and the potential drop $\left(\Delta \Psi^{ \pm}\right)$near the electrode surface. The surface charge is the average total charge on the electrode divided by the surface area of the graphene layer. The electrostatic potential along the simulation box is taken from the 1D Poisson's equation: ${ }^{86,87}$

$$
\Psi(z)=-\frac{1}{\epsilon_{0}} \int_{z_{0}}^{z}\left(z-z^{\prime}\right) \rho_{z}(z) d z^{\prime}
$$

where $\rho_{z}$ is the local charge density of the role system.

The potential drop of each electrode is defined by following equation: ${ }^{86,87}$

$$
\Delta \Psi^{ \pm}=\Psi^{ \pm}-\Psi_{b u l k}-\Psi_{P Z C}
$$

where the $\Psi_{P Z C}$ is the potential of zero charge. Therefore, the differential capacitance on a given electrode is obtained from the change rate of the surface charge density with respect to the potential drop of the electrode: ${ }^{86,87}$

$$
C_{d}=\frac{d \rho_{e l e}^{ \pm}}{d \Psi^{ \pm}}
$$




\section{Results and Discussion}

\subsection{Validation of interaction param- eters for $\left[\mathbf{S}_{12 G 1}\right]\left[\mathbf{N T f}_{2}\right]$}

It is well-recognized that molecular simulations of ionic liquids employing nonpolarizable force field and formal charge equal to $|1,0 \mathrm{q}|$ fail to predict transport properties (diffusion coefficient, ionic conductivity, and viscosity), reaching differences up to one order of magnitude. ${ }^{88,89}$ The scaled-charge approach $(q=|0.8 \mathrm{e}|)$ of neat ionic liquids reproduces appropriatly structure, transport properties, and thermodynamical properties. ${ }^{60-65}$ In fact, both ionic conductivity and viscosity obtained from the simulations are in good agreement with their respective experimental data ${ }^{36}$ in a wide range of temperature, Figure 2.
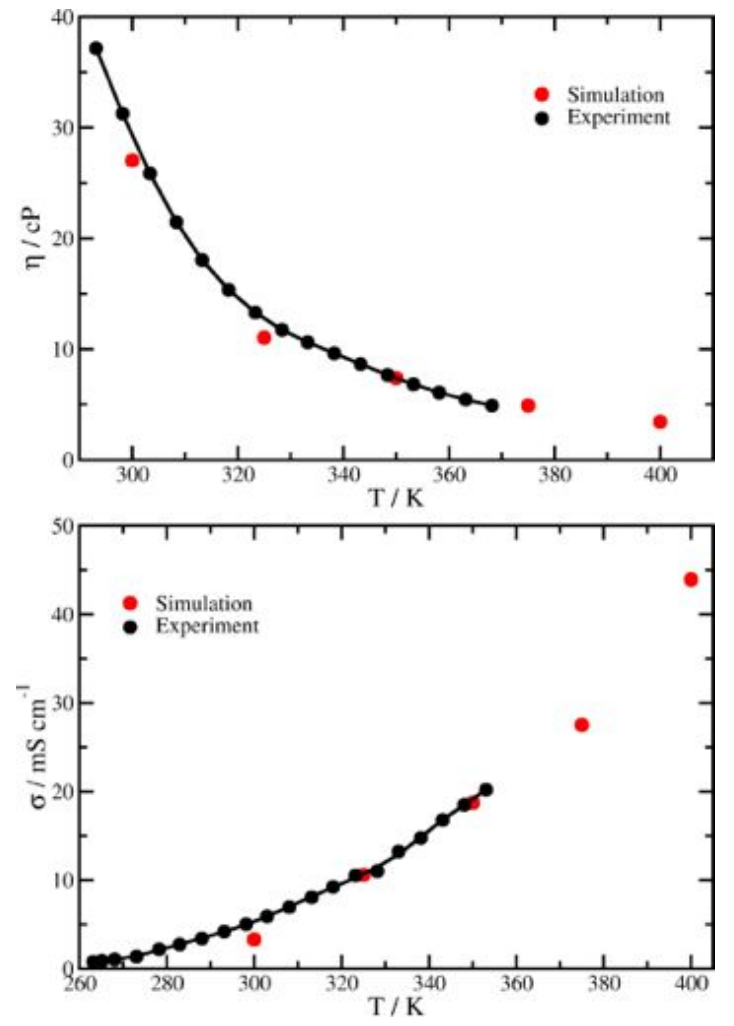

Figure 2: Experimental and calculated viscosity (upper panel) and ionic conductivity (bottom panel) in a wide range of temperature

Table 1 shows that increasing the amount of $\mathrm{ACN}$, the ionic conductivity increases up to 7 times in comparison with neat ionic liquid. In accordance, the ionic conductivity calculated for short-tailed imizadolium ionic liquids is 5 to 10 times higher in mixtures containing 20 to $10 \%$ of IL. ${ }^{39}$ Given the inverse relation between ionic conductivity and viscosity, the neat ionic liquid is around 26 times more viscous than the more diluted mixture $\left(x_{A C N}=0.88\right)$. The experimental viscosity of $\left[\mathrm{S}_{12 \mathrm{G1}}\right]\left[\mathrm{NTf}_{2}\right]$ is $\sim 26 \mathrm{cP}$ at $300 \mathrm{~K}$, which is in excellent agreement with calculated here $(\sim 27$ $\mathrm{cP})$.

The $\sigma_{\text {calc }} / \sigma^{N E}$ ratio accounts for the cross correlation among the ions in the liquid. For systems with $x_{A C N}$ equals to $0.00,0.50$, and 0.88 , the respectively $\sigma_{\text {calc }} / \sigma^{N E}$ values are 0.56 , $0.51,0.52$. Typical values of the ratio $\sigma_{\text {calc }} / \sigma^{N E}$ for ionic liquids is around 0.5 for ionic liquids and simpler molten salts. Note that, even in $x_{A C N}=0.88$, the cross correlation among the ions is still relevant. In the neat ionic liquid $\left(x_{A C N}=0.00\right)$ and $x_{A C N}=0.50$ mixture, the diffusion coefficients of the $\left[\mathrm{S}_{12 \mathrm{G} 1}\right]^{+}$are larger than the diffusion coefficient of the $\left[\mathrm{NTf}_{2}\right]^{-}$, which is accounting for the smaller mass of former. Conversely, in the $x_{A C N}=0.88$ mixture, anions have larger diffusion coefficient than cations, which might be a consequence of the local structure of the anions in the mixtures.

Table S8 of the supporting information shows the experimental ${ }^{36}$ and the calculated densities for the neat $\left[\mathrm{S}_{12 \mathrm{G} 1}\right]\left[\mathrm{NTf}_{2}\right]$ at different temperatures and its mixtures with acetonitrile at $300 \mathrm{~K}$. The calculated densities for the neat ionic liquid are in good agreement with the experimental ones, presenting deviation below 3\%, which was also found in previous studies. ${ }^{90-92}$ The addition of $\mathrm{ACN}$ in the ionic liquid decreases the density, following the experimental and calculated data available for imidazolium-based ionic liquids. ${ }^{39,44-46,65,93-98}$

Table S9 on the supporting information shows the total intermolecular energy between cation and anion up to the distance of $1.5 \mathrm{~nm}$ $\left(\mathrm{r}_{\text {cut }}=1.5 \mathrm{~nm}\right)$ for the neat ionic liquid and its mixtures with acetonitrile at $300 \mathrm{~K}$. The increase of acetonitrile mole fraction in the mix- 
Table 1: Experimental ${ }^{36}$ and calculated transport properties at $300 \mathrm{~K}$. The viscosities $(\eta)$, ionic conductivities $(\sigma)$, and diffusion coefficients (D) are in $\mathrm{cP}, \mathrm{mS} \mathrm{cm}{ }^{-1}$, and $10^{-7} \mathrm{~cm}^{2} \mathrm{~s}^{-1}$, respectively. The deviations are in parenthesis.

\begin{tabular}{cccccccc}
\hline$x_{A C N}$ & $\eta_{\text {calc }}$ & $\eta_{\text {exp }}{ }^{36}$ & $\sigma_{\text {calc }}$ & $\sigma_{\text {exp }}{ }^{36}$ & $\sigma^{N E}$ & $\mathrm{D}_{\text {cation }}$ & $\mathrm{D}_{\text {anion }}$ \\
\hline \multirow{2}{*}{0.00} & 26.932 & 25.860 & 3.640 & 5.92 & 6.46 & 4.290 & 3.340 \\
& $(0.147)$ & & $(0.180)$ & & & $(0.060)$ & $(0.100)$ \\
\multirow{2}{*}{0.50} & 10.365 & - & 8.550 & - & 16.87 & 12.520 & 10.960 \\
& $(0.059)$ & & $(0.280)$ & & & $(0.250)$ & $(0.280)$ \\
\multirow{2}{*}{0.88} & 1.006 & - & 25.130 & - & 48.02 & 60.850 & 73.350 \\
& $(0.003)$ & & $(0.450)$ & & & $(7.83)$ & $(8.92)$ \\
\hline
\end{tabular}

tures results in the weakening of the cationanion interaction, which is consistent with the decrease of the average number of ion pairs in the first neighbor shell.

Considering the reliability of the interaction parameters in describing properly transport properties, we will discuss in the next sections structure and supercapacitors performances of these systems.

\subsection{Structure}

An important feature in the structure of ionic liquids is that they exhibit an equilibrium structure very similar to that of simple molten salts, for instance, $\mathrm{NaCl} .{ }^{88,99}$ Figure 3 shows the radial distribution functions, $\mathrm{g}(\mathrm{r})$, calculated for the center of mass of the ions in the neat ionic liquid and the mixtures with acetonitrile at $300 \mathrm{~K}$. The cation-anion correlations appear around $0.5 \mathrm{~nm}$, while the cation-cation and anion-anion interactions appear at farther distances, $0.8 \mathrm{~nm}$. In spite of the ether function in one of the chains, the characteristic feature present by the $\mathrm{g}(\mathrm{r})$ (black lines) is typical of simple molten salts and ionic liquids, that is, where there is a minimum value in the cation-anion correlation curves, there is a peak in the cation-cation and anion-anion correlations. These correlations become less pronounced with the progressive addition of $\mathrm{ACN}$, indicating the partial disruption of the charge ordering.

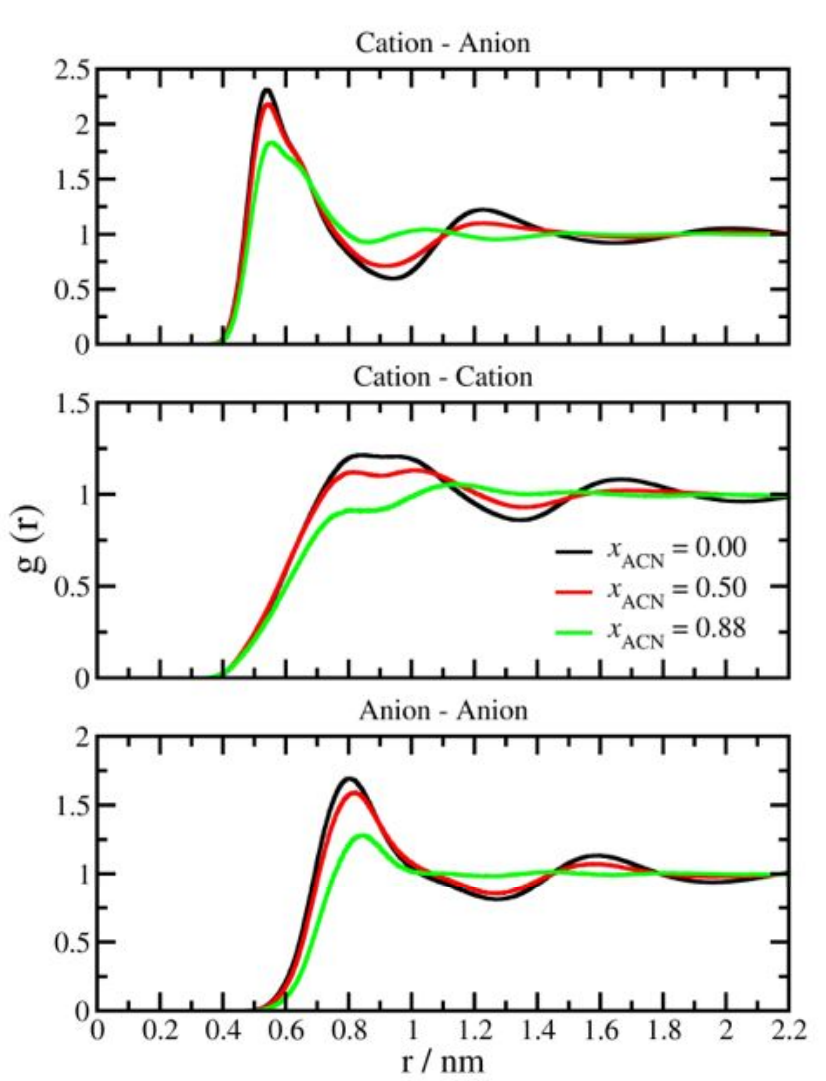

Figure 3: Radial distribution functions calculated for the center of mass of the ions in the different electrolytes at $300 \mathrm{~K}$.

Considering that the oxygen atoms of $\left[\mathrm{NTf}_{2}\right]^{-}$bears the more negative charges, these atoms likely develops stronger interactions with the positively charged atoms of 
$\left[\mathrm{S}_{12 \mathrm{G1}}\right]^{+}$. Figure 4a depicts the atomic correlations between $\mathrm{O}_{\text {anion }}$ and the carbon atoms of the sulfonium cations in neat ionic liquid, which appear around $0.35 \mathrm{~nm}$. The less intense correlation peaks arise from the carbon atoms directly bonded to the to $\mathrm{O}_{\text {ether }}$, which repeal the negatively charged atoms of $\left[\mathrm{NTf}_{2}\right]^{-}$. On the other hand, the stronger and more frequent interaction occurs between $\mathrm{C}_{a}-\mathrm{O}_{\text {anion }}$ due to the larger positive partial charge of $\mathrm{C}_{a}$ in comparison with the others carbon atoms of $\left[\mathrm{S}_{12 \mathrm{G} 1}\right]^{+}$. Upon addition of ACN to the ionic liquid, this correlation becomes less intense, accounting for the decrease of ion pairs interactions, Figure $4 \mathrm{~b}$. It is worth mentioning that the opposite trend had been observed in the simulations of 1-ethyl-3-methyl-imidazolium tetrafluoroborate $[\mathrm{EMIM}]\left[\mathrm{BF}_{4}\right] \cdot{ }^{39}$ This feature might be related to the hydrophobic nature of $\left[\mathrm{NTf}_{2}\right]^{-}$which allows for better solvation of $\left[\mathrm{NTf}_{2}\right]^{-}$by ACN molecules.
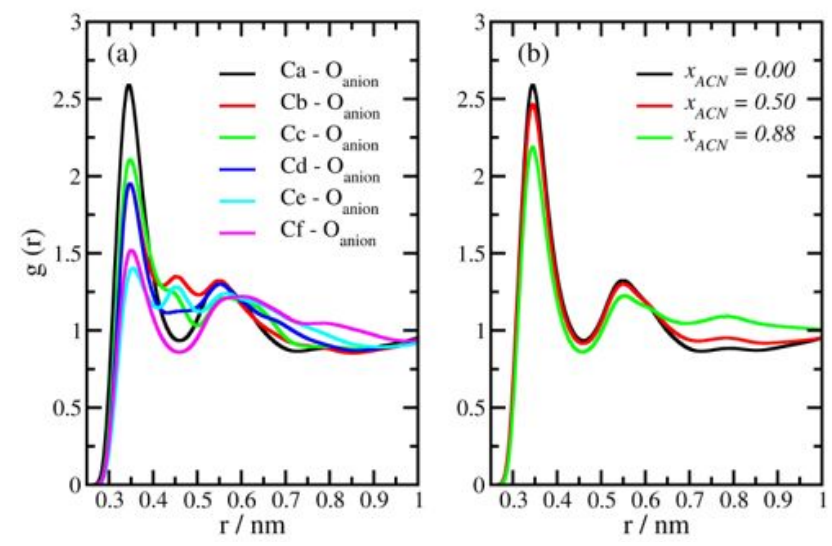

Figure 4: Radial distribution function between the $\mathrm{O}_{\text {anion }}$ and the carbon atoms of cations in neat $\left[\mathrm{S}_{12 \mathrm{G}}\right]\left[\mathrm{NTf}_{2}\right]$ at $300 \mathrm{~K}$ (left panel) and radial distribution function between $\mathrm{Ca}$ and $\mathrm{O}_{\text {anion }}$ in $\mathrm{ACN}$ mixtures (right panel).

Figure 5 shows the radial distribution functions calculated between the nitrogen atom of $\operatorname{ACN}\left(\mathrm{N}_{A C N}\right)$ and carbon atom of $\left[\mathrm{S}_{12 \mathrm{G} 1}\right]^{+}$(left panel) and between $\mathrm{CH}_{3}$ group of $\mathrm{ACN}$ and $\mathrm{N}_{\text {anion }}, \mathrm{O}_{\text {anion }}, \mathrm{F}_{\text {anion }}$ (right panel). Around 0.34 $\mathrm{nm}$, strong correlations of $\mathrm{N}_{A C N}$ occur with $\mathrm{C}_{a}$ (strongest), $\mathrm{C}_{b}, \mathrm{C}_{c}$, and $\mathrm{C}_{d}$, whereas the weaker ones involve $\mathrm{C}_{e}$ and $\mathrm{C}_{f}$ that are atoms bonded to $\mathrm{O}_{\text {ether }}$. Note that similar feature has been found for the correlations of $\mathrm{O}_{\text {anion }}$ and the carbon atoms of $\left[\mathrm{S}_{12 \mathrm{G} 1}\right]^{+}$discussed above. The $\mathrm{CH}_{3}$ group of $\mathrm{ACN}$ develops stronger correlations with $\mathrm{O}_{\text {anion }}$ and $\mathrm{F}_{\text {anion, }}$, around $0.34 \mathrm{~nm}$. Only a shoulder appears at this distance for $\mathrm{CH}_{3}-\mathrm{N}_{\text {anion }}$ correlations. Proper to the large number of solvent molecules in the system, in $x_{A C N}=0.88$, the number of ACN molecules solvating the ions is larger than that found in $x_{A C N}=0.50$, Table S10 of the supponting information.
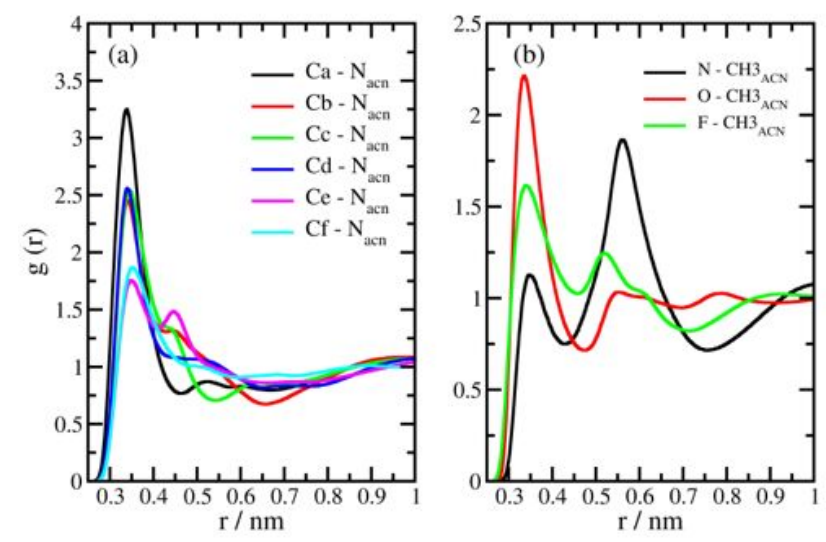

Figure 5: Radial distribution functions calculated for the correlations between $\mathrm{N}_{A C N}$ and carbon atoms of $\left[\mathrm{S}_{12 \mathrm{G} 1}\right]^{+}$(left panel), together with correlations between $\mathrm{CH} 3_{A C N}$ and $\mathrm{N}, \mathrm{O}$, $\mathrm{F}$ atoms of $\left[\mathrm{NTf}_{2}\right]^{-}$(right panel) at $300 \mathrm{~K}$

In order to provide more details about the local structure of the ions, we calculated spatial distribution functions (SDF) of cations and anions, Figure 6 . In the neat ionic liquid, the anions (red surfaces) are mainly arranged around the sulfur atom of cations, avoiding the region of $\mathrm{O}_{\text {ether }}$ due to the repulsion between negative charges (Figure 6a). The green regions represent the spatial distribution of cations around the $\left[\mathrm{NTf}_{2}\right]^{-}$. The cations are mainly located close to the region of oxygen atoms of sulfonyl groups, which bear high negative charges. In spite of the negative charges of $F$ atoms, the cations do not cover completely the region close to $\mathrm{CF}_{3}$ groups of $\left[\mathrm{NTf}_{2}\right]^{-}$. The larger the amount of $\mathrm{ACN}$ in the mixture, the narrower the surface of cations around the sulfonyl groups of $\left[\mathrm{NTf}_{2}\right]^{-}$, suggesting that ACN molecules displace the cations that de- 
velops weak interactions with $\mathrm{CF}_{3}$ group in neat IL. The SDF of anions around $\left[\mathrm{S}_{12 \mathrm{G} 1}\right]^{+}$ seems to be less sensitive to presence of ACN, since the red surfaces only presents subtle changes. The transparent cyan surfaces represent the regions where ACN molecules can be found around both the ions. Note that $\mathrm{ACN}$ molecules can arrange in the same region where there are counter-ions. Given the hydrophobic nature of $\mathrm{CF}_{3}$, the $\mathrm{ACN}$ molecules can also be found in its neighborhood, so that, the ACN molecules wrap the entire $\left[\mathrm{NTf}_{2}\right]^{-}$ (more evident in $x_{A C N}=0.88$ ). This arrangement might be the root for the higher diffusion coefficient of $\left[\mathrm{NTf}_{2}\right]^{-}$in $x_{A C N}=0.88$ in comparison with diffusion coefficient of lighter $\left[\mathrm{S}_{12 G 1}\right]^{+}$.
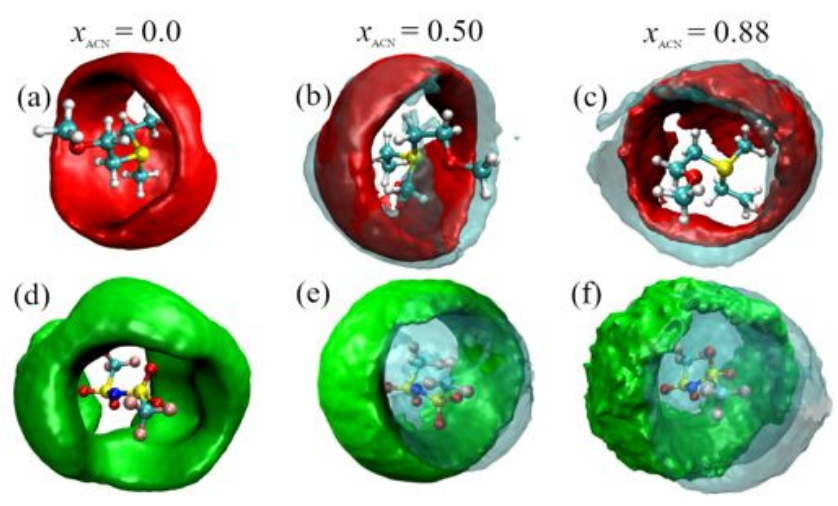

Figure 6: Spatial distribution functions of counter ions and $\mathrm{ACN}$ around the $\left[\mathrm{S}_{12 \mathrm{G} 1}\right]^{+}$ and $\left[\mathrm{NTf}_{2}\right]^{-}$. The red, green and transparentcyan surface account for the anions around cations, cations around anions and $\mathrm{ACN}$ around both the ions, respectively.

\subsection{Ionic Structure Near The Elec- trodes}

An important feature of the supercapacitors is the structure of ions near de surface of the electrode since the performance of the device depends fundamentally on the coulombic interaction between the ions and the electrode atoms. We investigated the ionic structure near the graphite electrode by the number density profiles of the $\left[\mathrm{S}_{12 \mathrm{G} 1}\right]\left[\mathrm{NTf}_{2}\right]$ ionic liquid and its solutions with acetonitrile along the simulation box.

Figure 7 shows the number density profile of the pure ionic liquid confined between the two graphite electrodes. At $\Delta \Psi=0 \mathrm{~V}$, anions and cations are adsorbed on the surface of both electrodes. Increasing the applied voltage part of the co-ions are expelled from the region near to the electrode surface with attraction of counter-ions to the electrode. For instance, at $\Delta \Psi=3 \mathrm{~V}$, one can clear observe two distinct alternated layers close to negative electrode extending up to $2.5 \mathrm{~nm}$ from it, whereas in the positive electrode, the multilayers are less evident, where there is a considerable number of cations adsorbed onto the positive surface. Similar behavior has been observed in the simulations of a phosphonium-based ionic liquid, although less pronounced. ${ }^{55}$ In the mixtures with acetonitrile, there are one sharp layer of the ions close to the electrode surfaces, Figures S2 and S3 of the supplementary information. These figures also show that acetonitrile has high affinity to the electrode as there are high density of the solvent indicating its adsorption onto the electrodes surface. Note that they do not change remarkably with applied voltage. In fact, these finding is also consistent with previous simulations of tetra-ethylammonium tetra-fluoroborate $\left[\mathrm{N}_{2222}\right]\left[\mathrm{BF}_{4}\right]$ solutions in acetonitrile. ${ }^{100}$
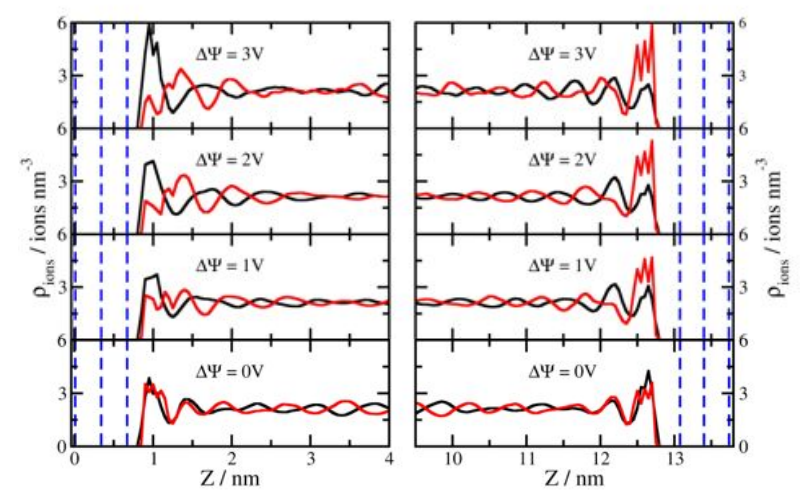

Figure 7: Number density profile of the pure $\left[\mathrm{S}_{12 \mathrm{G} 1}\right]\left[\mathrm{NTf}_{2}\right]$ ionic liquid. The blue dot lines represent the graphite sheets of each electrode. 
Integrating the number density of ions multiplied by the area of the electrode up to a distance of $\sim 1 \mathrm{~nm}$ from the electrode, one obtains the number of ions adsorbed onto the electrode surfaces, Table 2 . In both the electrodes and in all the electrolytes, the number of counter-ions in the first layer increases, whereas the number co-ions decreases with the increase of the applied voltage, which indicates that ion exchange on the electrode surface is the main cause for the charge accumulation on the planar electrodes. In $x_{A C N}=0.5$ and 0.88 , the number of co-ions inside the $1 \mathrm{~nm}$ thick layer close to electrode is the lower than the number of counter-ion found in neat ionic liquid at given voltage. At $\Delta \Psi=3 \mathrm{~V}$, the surface of the electrode are almost covered by counterion and acetonitrile. Similar behavior was observed for the $[\mathrm{BMI}]\left[\mathrm{BF}_{4}\right]$ and $[\mathrm{BMI}]\left[\mathrm{PF}_{6}\right]$ ionic liquids mixtures with acetonitrile. ${ }^{101}$

\subsection{Capacitances and Charging Dy- namics}

Besides its realistic treatment of the charge fluctuation on the electrode due to electrolyte in its neighborhood, the potential constant method applied in our simulations can also account successfully for the charging dynamics, as demonstrated in the simulations of porous carbon electrodes. ${ }^{56,57,102}$ Here, the last configuration of the simulation at $\Delta \Psi=0 \mathrm{~V}$ was used as starting configuration in all the applied voltages. Figure 8 shows the evolution of the charge density on the positive electrode for the supercapacitor with $x_{A C N}=0.00$. After 3500 ps the planar electrode is almost in its maximum state of charge when the elec-

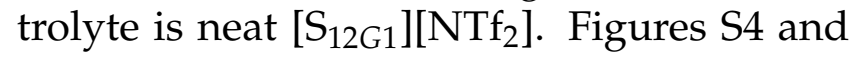
Figure S5 of the Support Information show the evolution of the charge for supercapacitors built with acetonitrile mixtures. Proper to lower viscosities (higher ionic conductivities) of the mixtures, their supercapacitors present faster charging dynamics in comparison with neat ionic liquid, that is, before 2000 ps the charge accumulated on the electrode has already reached a plateau.

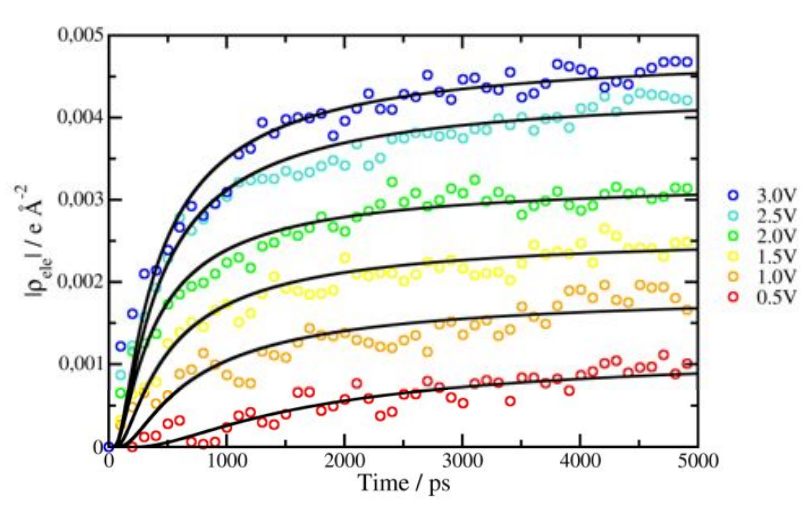

Figure 8: Evolution of the charge density on the electrodes during the charging process for the neat $\left[\mathrm{S}_{12 \mathrm{G} 1}\right]\left[\mathrm{NTf}_{2}\right]$ ionic liquid

In the study of charging dynamics of porous carbon electrode, $56,57,102$ the authors used a biexponential function to fit the evolution of the charge accumulated on the electrode. Considering that planar electrodes are simpler than the porous ones, a mono-exponential equation has been fitted to the surface charge density as a function of simulation time in order to quantify the relaxation charging time $(\tau)$ and the maximum charge density accumulated on the electrode $\left(\rho_{\max }\right)$,

$$
\rho(t)=\rho_{\max } \cdot \exp \left(\frac{-\tau}{t}\right) .
$$

The black curves over the dotted points in Fig. 8 depicts the good quality of the monoexponential curves fitting. Table 3 shows the maximum charge density accumulated on the electrode $\left(\rho_{\max }\right)$ and relaxation charging times obtained from the fittings.

Table 4 shows the differential capacitances calculated from the slope of the straight lines fitted to the electrode charge density as a function of the potential drop, which are presented in Fig. S6 of the supporting information.

The differential capacitances obtained for neat $\left[\mathrm{S}_{12 \mathrm{G1}}\right]\left[\mathrm{NTf}_{2}\right]$ and its mixtures with acetonitrile are in excellent agreement with those calculated for imidazolium-based ionic liquids electrolytes. ${ }^{101}$ Due to the asymmetry of the ions, the capacitance of positive and negative electrodes are different. ${ }^{55,101}$ A common ef- 
Table 2: Average number of ions and acetonitrile distant up to $1 \mathrm{~nm}$ from the surface of the electrodes. $\mathbf{N}_{c a t}{ }^{+}, \mathbf{N}_{a n}{ }^{+}$and $\mathbf{N}_{a c n}{ }^{+}$represents the number of cations, anions and acetonitrile molecules at the positive electrode. $\mathbf{N}_{c a t}{ }^{-}, \mathbf{N}_{a n}{ }^{-}$and $\mathbf{N}_{a c n}{ }^{-}$represents the number of cations, anions and acetonitrile molecules at the negative electrode.

\begin{tabular}{|c|c|c|c|c|c|c|c|}
\hline$\Delta \Psi$ & $x_{A C N}$ & $\mathrm{~N}_{c a t}{ }^{-}$ & $\mathrm{N}_{a n}{ }^{-}$ & $\mathrm{N}_{a c n}{ }^{-}$ & $\mathrm{N}_{c a t}{ }^{+}$ & $\mathrm{N}_{a n}{ }^{+}$ & $\mathrm{N}_{a c n}{ }^{+}$ \\
\hline \multirow{3}{*}{$0.0 \mathrm{~V}$} & 0.00 & 11.8 & 12.5 & - & 10.9 & 10.1 & - \\
\hline & 0.50 & 10.5 & 8.9 & 12.5 & 8.8 & 7.9 & 10.8 \\
\hline & 0.88 & 6.1 & 5.4 & 36.5 & 6.0 & 4.3 & 29.9 \\
\hline \multirow{3}{*}{$0.5 \mathrm{~V}$} & 0.00 & 12.3 & 11.7 & - & 10.9 & 10.1 & - \\
\hline & 0.50 & 11.8 & 8.3 & 6.3 & 8.8 & 10.6 & 6.9 \\
\hline & 0.88 & 7.8 & 4.4 & 29.3 & 6.0 & 5.4 & 28.9 \\
\hline \multirow{3}{*}{$1.0 \mathrm{~V}$} & 0.00 & 13.1 & 10.5 & - & 8.3 & 13 & - \\
\hline & 0.50 & 12.3 & 7.9 & 11.3 & 6.9 & 10.0 & 10.3 \\
\hline & 0.88 & 7.3 & 4.1 & 37.4 & 3.9 & 4.8 & 32.5 \\
\hline \multirow{3}{*}{$1.5 \mathrm{~V}$} & 0.00 & 13.1 & 9.2 & - & 8.9 & 13.8 & - \\
\hline & 0.50 & 12.1 & 7.5 & 4.6 & 7.1 & 11.5 & 8.7 \\
\hline & 0.88 & 7.4 & 2.3 & 35.7 & 2.3 & 5.9 & 37.4 \\
\hline \multirow{3}{*}{$2.0 \mathrm{~V}$} & 0.00 & 14.1 & 9.1 & - & 7.7 & 13.8 & - \\
\hline & 0.50 & 13.7 & 6.9 & 9.5 & 5.1 & 10.7 & 14.0 \\
\hline & 0.88 & 10.5 & 3.2 & 31.1 & 2.5 & 4.7 & 37.2 \\
\hline \multirow{3}{*}{$2.5 \mathrm{~V}$} & 0.00 & 14.2 & 7.4 & - & 7.8 & 15.3 & - \\
\hline & 0.50 & 12.7 & 5.7 & 7.1 & 6.1 & 11.7 & 12.5 \\
\hline & 0.88 & 9.7 & 1.4 & 31.9 & 1.9 & 6.0 & 40.0 \\
\hline \multirow{3}{*}{$3.0 \mathrm{~V}$} & 0.00 & 16.0 & 8.3 & - & 7.1 & 14.2 & - \\
\hline & 0.50 & 14.8 & 5.5 & 10.3 & 4.5 & 13.3 & 9.3 \\
\hline & 0.88 & 11.0 & 2.0 & 33.2 & 1.4 & 7.4 & 34.8 \\
\hline
\end{tabular}

fect of adding acetonitrile in ionic liquids is the small increase of differential capacitance of positive electrode and subtle changes in negative electrode, in agreement with previous simulations that use constant potential model to consider polarization of planar electrodes. ${ }^{100,101}$ In the presence of the organic solvent, the ions are less correlated due to the decrease of the ion-ion interaction provided by the solvation so that they can easier probe the electric field applied on the electrodes. ${ }^{100,101}$
Neto and Fileti ${ }^{51}$ found in their simulations of [EMIM] $\left[\mathrm{C}(\mathrm{CN})_{3}\right]$ mixtures with acetonitrile differential capacitance on the negative electrode spanning from 4.3 to $14 \mu \mathrm{F} \mathrm{cm}^{-2}$ increasing the amount of the solvent. This finding might be linked to constant charge simulations performed in their simulations.

For the neat $\left[\mathrm{S}_{12 \mathrm{G1}}\right]\left[\mathrm{NTf}_{2}\right], \tau$ decreases almost monotonically from 1500 ps $(\Delta \Psi=0.5 \mathrm{~V})$ to $300 \mathrm{ps}(\Delta \Psi>2 \mathrm{~V})$, Figure 9 . It is worth mention, that the shape of $\tau$ versus applied 
Table 3: $\tau$ (ps) values and $\rho_{\max }\left(10^{-3} \mathbf{e} \AA^{-2}\right)$ for the three different systems simulated.

\begin{tabular}{ccccccc}
\hline \multirow{2}{*}{$\Delta \Psi$} & \multicolumn{2}{c}{$x_{A C N}=0.00$} & \multicolumn{3}{c}{$x_{A C N}=0.50$} & \multicolumn{2}{c}{$x_{A C N}=0.88$} \\
& $\tau$ & $\rho_{\max }$ & $\tau$ & $\rho_{\max }$ & $\tau$ & $\rho_{\max }$ \\
\cline { 2 - 7 } $0.5 \mathrm{~V}$ & 1541.9 & 1.2 & 91.83 & 1.0 & 26.4 & 0.9 \\
$1.0 \mathrm{~V}$ & 597.9 & 1.9 & 143.4 & 2.1 & 48.2 & 1.7 \\
$1.5 \mathrm{~V}$ & 412.4 & 2.3 & 137.9 & 3.0 & 40.5 & 2.8 \\
$2.0 \mathrm{~V}$ & 309.6 & 3.3 & 113.9 & 3.9 & 36.4 & 3.5 \\
$2.5 \mathrm{~V}$ & 337.9 & 4.4 & 75.48 & 4.5 & 38.0 & 4.5 \\
$3.0 \mathrm{~V}$ & 322.8 & 4.8 & 100.47 & 5.4 & 50.4 & 5.3 \\
\hline
\end{tabular}

voltage obtained here is rather different from that found in the simulations of [EMIM] [SCN] at $350 \mathrm{~K} .{ }^{54}$ In the mixtures, the higher the mole fraction of acetonitrile, the lower the $\tau$, which is reflecting the lower viscosity (higher ionic conductivity) of the mixtures. However, the behavior of $\tau$ with the applied voltage is completely different from that observed for IL, that is, the supercapacitors show the fastest charging at $\Delta \Psi=0.5 \mathrm{~V}$ and the slowest at $\Delta \Psi=1.0 \mathrm{~V}$.
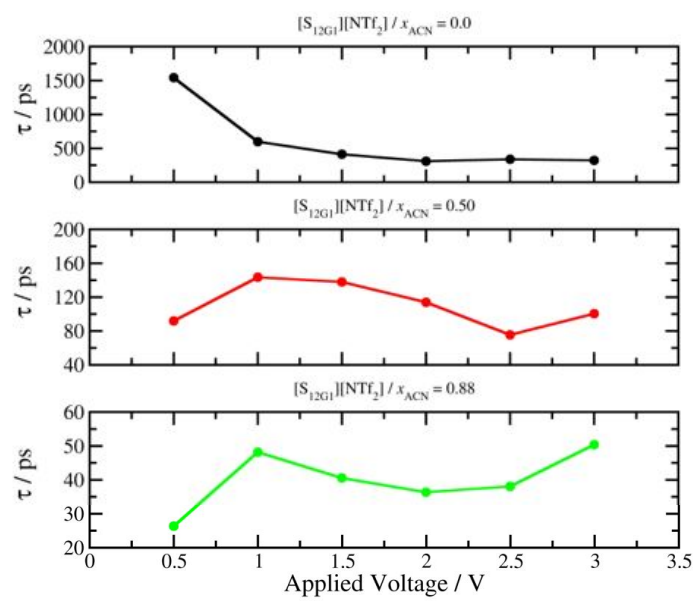

Figure 9: Relaxation charging times as function of the applied voltage $\Delta \Psi$

In order to understand these features, we calculated the average perpendicular displacement of $\alpha$ ions with respect to planar electrode inside a layer of $1 \mathrm{~nm}$ close to the electrodes, $\mathrm{z}^{\alpha},{ }^{54}$ as

$$
z^{\alpha}=\frac{1}{N^{\alpha}} \sum_{i=1}^{N^{\alpha}}\left[z_{i}^{\alpha}(t)-z_{i}^{\alpha}(0)\right]
$$
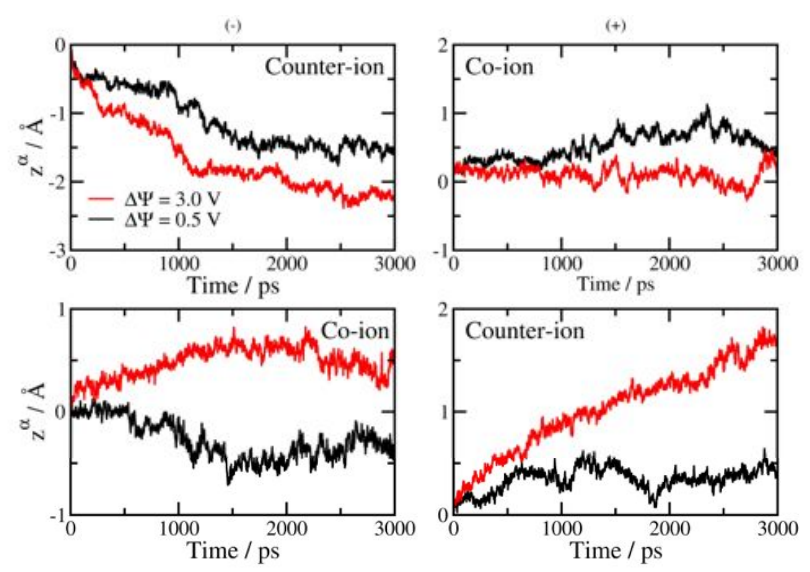

Figure 10: Average perpendicular displacement of ions with respect to the electrodes $\mathrm{z}^{\alpha}$ for the neat $\left[S_{12 G 1}\right]\left[\mathrm{NTf}_{2}\right]$ ionic liquid.

where $\mathrm{N}^{\alpha}$ is the number of $\alpha$ ions inside the layer and $\mathrm{z}_{i}^{\alpha}$ is the $\mathrm{z}$ component of the $i$ th $\alpha$ ion position at time t. Figure 10 shows how $\mathrm{z}_{i}^{\alpha}$ calculated for counter-ion and co-ion behaves close to the surface of negative and positive electrodes using neat $\left[\mathrm{S}_{12 \mathrm{G} 1}\right]\left[\mathrm{NTf}_{2}\right]$ as electrolyte. At $\Delta \Psi=0.5 \mathrm{~V}$, counter-ions and coions present very small displacements along the z-axis, whereas at higher applied potential $(\Delta \Psi=3.0 \mathrm{~V})$ the counter-ions present larger displacements towards the electrode surfaces. These findings indicate that, at low applied voltage, the electrodes charge slowly due to ion's rearrangement in the vicinity of the electrodes. However, when the applied voltage is high, there is enough energy to perturb the structure of the ions initially adsorbed onto the electrode, so that the charging is faster due the diffusion of ions across the electrolyte. For instance, the negative and positive displacements of counter-ions and co-ions, respectively, on the negative electrode indicates that it charges by counter-ions adsorption and ionexchange mechanisms. Considering that coions present negligible displacement on the positive electrode at $\Delta \Psi=3.0 \mathrm{~V}$, counter-ion adsorption is the main mechanism of charging on positive electrode. Similarly, Noh and Jung 54 found that low voltage the charging is slow and proceeds by ion's arrangement close to the electrodes. At high voltages, however, they found that the charging of electrode is largely dependent of co-ions desorption. 
Table 4: Differential capacitances on the positive and negative electrodes for the $\left[\mathrm{S}_{12 G 1}\right]\left[\mathbf{N T f}_{2}\right]$ ionic liquid, its solutions with acetonitrile, imidazolium based ionic liquids and a phosphonium based ionic liquid. In parenthesis are the error bars. The authors of the study with the phosphonium based ionic liquid do not provide the diferential capacitance errors measurement.

\begin{tabular}{|c|c|c|}
\hline Electrolyte & $\mathrm{C}^{+}\left(\mu \mathrm{F} \mathrm{cm}^{-2}\right)$ & $\mathrm{C}^{-}\left(\mu \mathrm{F} \mathrm{cm}^{-2}\right)$ \\
\hline$\left[\mathrm{S}_{12 \mathrm{G} 1}\right]\left[\mathrm{NTf}_{2}\right] / x_{A C N}=0.00$ & $3.6( \pm 0.2)$ & $5.0( \pm 0.2)$ \\
\hline$[\mathrm{BMI}]\left[\mathrm{BF}_{4}\right]^{101}$ & $3.9( \pm 0.3)$ & $5.5( \pm 0.1)$ \\
\hline$[\mathrm{BMI}]\left[\mathrm{PF}_{6}\right]^{101}$ & $3.9( \pm 0.3)$ & $4.8( \pm 0.5)$ \\
\hline$\left[\mathrm{S}_{12 \mathrm{G} 1}\right]\left[\mathrm{NTf}_{2}\right] / x_{A C N}=0.50$ & $4.7( \pm 0.2)$ & $5.5( \pm 0.3)$ \\
\hline$\left[\mathrm{S}_{12 \mathrm{G} 1}\right]\left[\mathrm{NTf}_{2}\right] / x_{A C N}=0.88$ & $4.6( \pm 0.1)$ & $5.0( \pm 0.3)$ \\
\hline$[\mathrm{BMI}]\left[\mathrm{BF}_{4}\right]-\mathrm{ACN}^{101}$ & $4.8( \pm 0.2)$ & $4.3( \pm 0.2)$ \\
\hline$[\mathrm{BMI}]\left[\mathrm{PF}_{6}\right]-\mathrm{ACN}^{101}$ & $4.6( \pm 0.2)$ & $4.6( \pm 0.2)$ \\
\hline
\end{tabular}

Almost the same findings can be verified in the mixtures of $\left[\mathrm{S}_{12 \mathrm{G1}}\right]\left[\mathrm{NTf}_{2}\right]$ with acetonitrile, regarding the average displacement along the z-axis and the charging mechanism (See Figure S7 and S8 of the Supporting Information), however their effects to the relaxation charging time $(\tau)$ is opposite to that found for neat ionic liquids. At low voltage, the sharp layer of acetonitrile adsorbed on the surface of the electrodes favour the ion's reagements in the vicinity of the electrode, but it acts as barrier to ion-exchange at higher voltages.

\section{Conclusions}

Atomistic molecular dynamics simulations and a scaled-charge model for the ions successfully describe collective transport properties of neat $\left[S_{12 G 1}\right]\left[\mathrm{NTf}_{2}\right]$ in a wide range of temperature. The addition of ACN weakens the ion pair interaction, partially disrupting the typical charge ordering structure of ionic liquids. Thus, the addition of ACN decreases viscosity (increases ionic conductivity), which results in the improvement of the performance of the supercapacitors in terms of power, without loosing the capacitance performance. At low voltage, the rearrangements of ions close to electrodes responsible to the charge accu- mulation is very slow in neat $\left[\mathrm{S}_{12 \mathrm{G}}\right]\left[\mathrm{NTf}_{2}\right]$. The sharp layer of ACN makes this rearrangement easier (fast), but it acts as a barrier to ion exchange at higher voltages, which increase the charging time. The charge accumulated on the electrodes proceeds by ion exchange and counter-ion adsorption at high applied voltage.

Acknowledgement The authors gratefully acknowledge support from FAPESP (São Paulo Research Foundation, Grant Number 2017/11631-2), Shell, the strategic importance of the support given by ANP (Brazil's National Oil, Natural Gas and Biofuels Agency) through the R\&D levy regulation and $\mathrm{CNPq}$ (National Council for Scientific and Technological Development). This work also used resources of the "Centro Nacional de Processamento de Alto Desempenho em São Paulo (CENAPAD-SP)." This study was also financed in part by the Coordenação de Aperfeiçoamento de Pessoal de Nível Superior - Brasil (CAPES) - Finance Code 001. 


\section{Supporting Information Avail- able}

All the parameters of the force field for cation, anion and acetonitrile can be found in the Tables S1-S6 in the Support Information file. This material is available free of charge.

\section{References}

(1) Martins, V. L.; Torresi, R. M. Ionic liquids in electrochemical energy storage. Current Opinion in Electrochemistry 2018, 9, 26-32.

(2) Liu, H.; Yu, H. Ionic liquids for electrochemical energy storage devices applications. Journal of Materials Science $\mathcal{E}$ Technology 2019, 35, 674-686.

(3) Lewandowski, A.; Świderska-Mocek, A. Ionic liquids as electrolytes for Li-ion batteries-An overview of electrochemical studies. Journal of Power Sources 2009, 194, 601-609.

(4) Galiński, M.; Lewandowski, A.; Stępniak, I. Ionic liquids as electrolytes. Electrochimica Acta 2006, 51, 5567-5580.

(5) Freire, M. G.; Santos, L. M.; Fernandes, A. M.; Coutinho, J. A.; Marrucho, I. M. An overview of the mutual solubilities of water-imidazolium-based ionic liquids systems. Fluid Phase Equilibria 2007, 261, 449-454.

(6) Freire, M. G.; Carvalho, P. J.; Gardas, R. L.; Marrucho, I. M.; Santos, L. M. N. B. F.; Coutinho, J. A. P. Mutual Solubilities of Water and the [C $\mathrm{n}$ mim][Tf 2 N] Hydrophobic Ionic Liquids. The Journal of Physical Chemistry B 2008, 112, 1604-1610.

(7) Oliveira, L. V.; Camilo, F. F. Facile synthesis of silver-polypyrrole nanocomposites: Use of ionic liquid as solvent and template. Synthetic Metals 2019, 247, 219227.
(8) Morais, T.; Coutinho, A. P.; Camilo, F.; Martins, T.; Sartorelli, P.; Massaoka, M.; Figueiredo, C.; Lago, J. H. Application of an Ionic Liquid in the Microwave Assisted Extraction of Cytotoxic Metabolites from Fruits of Schinus terebinthifolius Raddi (Anacardiaceae). Journal of the Brazilian Chemical Society 2016,

(9) Steinrück, H.-P.; Libuda, J.; Wasserscheid, P.; Cremer, T.; Kolbeck, C.; Laurin, M.; Maier, F.; Sobota, M.; Schulz, P. S.; Stark, M. Surface Science and Model Catalysis with Ionic LiquidModified Materials. Advanced Materials 2011, 23, 2571-2587.

(10) Cardoso, P. F.; Fernandez, J. S. L. C.; Lepre, L. F.; Ando, R. A.; Costa Gomes, M. F.; Siqueira, L. J. A. Molecular dynamics simulations of polyethers and a quaternary ammonium ionic liquid as $\mathrm{CO} 2$ absorbers. The Journal of Chemical Physics 2018, 148, 134908.

(11) Lepre, L.; Pison, L.; Siqueira, L.; Ando, R.; Costa Gomes, M. Improvement of carbon dioxide absorption by mixing poly(ethylene glycol) dimethyl ether with ammonium-based ionic liquids. Separation and Purification Technology 2018, 196, 10-19.

(12) Zubeir, L. F.; Lacroix, M. H.; Meuldijk, J.; Kroon, M. C.; Kiss, A. A. Novel pressure and temperature swing processes for $\mathrm{CO} 2$ capture using low viscosity ionic liquids. Separation and Purification Technology 2018, 204, 314-327.

(13) Hoher, K.; Cardoso, P. F.; Lepre, L. F.; Ando, R. A.; Siqueira, L. J. A. Molecular dynamics and a spectroscopic study of sulfur dioxide absorption by an ionic liquid and its mixtures with PEO. Phys. Chem. Chem. Phys. 2016, 18, 28901-28910.

(14) Li, H.; Somers, A. E.; Howlett, P. C.; Rutland, M. W.; Forsyth, M.; Atkin, R. Addition of low concentrations of an ionic liquid to a base oil reduces friction over 
multiple length scales: a combined nanoand macrotribology investigation. Physical Chemistry Chemical Physics 2016, 18, 6541-6547.

(15) Stroppa, P. H. F.; Martins, J. S.; Dias, R. C.; Salla, C. A.; Bechtold, I. H.; Legnani, C.; Fragneaud, B.; Quirino, W. G.; David da Silva, A. High efficient Light-Emitting Electrochemical Cells based on ionic liquids 1,2,3triazolium. Organic Electronics 2019, 73, 172-181.

(16) Yu, L.; Chen, G. Z. Ionic Liquid-Based Electrolytes for Supercapacitor and Supercapattery. Frontiers in Chemistry 2019, 7.

(17) Jiang, X.; Luo, L.; Zhong, F.; Feng, X.; Chen, W.; Ai, X.; Yang, H.; Cao, Y. Electrolytes for Dual-Carbon Batteries. ChemElectroChem 2019, 6, 2615-2629.

(18) Hagfeldt, A.; Boschloo, G.; Sun, L.; Kloo, L.; Pettersson, H. Dye-Sensitized Solar Cells. Chemical Reviews 2010, 110, 6595-6663.

(19) van de Ven, E.; Chairuna, A.; Merle, G.; Benito, S. P.; Borneman, Z.; Nijmeijer, K. Ionic liquid doped polybenzimidazole membranes for high temperature Proton Exchange Membrane fuel cell applications. Journal of Power Sources 2013, 222, 202-209.

(20) Li, B.; Wang, L.; Kang, B.; Wang, P.; Qiu, Y. Review of recent progress in solid-state dye-sensitized solar cells. Solar Energy Materials and Solar Cells 2006, 90, 549-573.

(21) Béguin, F.; Presser, V.; Balducci, A.; Frackowiak, E. Carbons and electrolytes for advanced supercapacitors. Advanced Materials 2014, 26, 2219-2251.

(22) Simon, P.; Gogotsi, Y. Materials for electrochemical capacitors. Nature Materials 2008, 7, 845-854.
(23) Simon, P.; Gogotsi, Y. Capacitive Energy Storage in Nanostructured CarbonElectrolyte Systems. Accounts of Chemical Research 2013,

(24) Merlet, C.; Salanne, M.; Rotenberg, B. New Coarse-Grained Models of Imidazolium Ionic Liquids for Bulk and Interfacial Molecular Simulations. The Journal of Physical Chemistry C 2012, 116, 76877693.

(25) Pohlmann, S.; Olyschläger, T.; Goodrich, P.; Vicente, J. A.; Jacquemin, J.; Balducci, A. Mixtures of Azepanium Based Ionic Liquids and Propylene Carbonate as High Voltage Electrolytes for Supercapacitors. Electrochimica Acta 2015, 153, 426-432.

(26) Eftekhari, A. Supercapacitors utilising ionic liquids. Energy Storage Materials 2017, 9, 47-69.

(27) Xiang, J.; Wu, F.; Chen, R.; Li, L.; Yu, H. High voltage and safe electrolytes based on ionic liquid and sulfone for lithiumion batteries. Journal of Power Sources 2013, 233, 115-120.

(28) Quartarone, E.; Mustarelli, P. Electrolytes for solid-state lithium rechargeable batteries: recent advances and perspectives. Chemical Society Reviews 2011, 40, 2525.

(29) Mastragostino, M.; Soavi, F. Strategies for high-performance supercapacitors for HEV. Journal of Power Sources 2007, 174, 89-93.

(30) Palm, R.; Kurig, H.; Tõnurist, K.; Jänes, A.; Lust, E. Is the mixture of 1-ethyl-3-methylimidazolium tetrafluoroborate and 1-butyl-3methylimidazolium tetrafluoroborate applicable as electrolyte in electrical double layer capacitors? Electrochemistry Communications 2012, 22, 203-206. 
(31) Salanne, M. Ionic Liquids for Supercapacitor Applications. Topics in Current Chemistry 2017, 375, 63.

(32) Han, H.-B.; Nie, J.; Liu, K.; Li, W.K.; Feng, W.-F.; Armand, M.; Matsumoto, H.; Zhou, Z.-B. Ionic liquids and plastic crystals based on tertiary sulfonium and bis(fluorosulfonyl)imide. Electrochimica Acta 2010, 55, 1221-1226.

(33) Rennie, A. J. R.; Martins, V. L.; Torresi, R. M.; Hall, P. J. Ionic liquids containing sulfonium cations as electrolytes for electrochemical double layer capacitors. Journal of Physical Chemistry C 2015, 119, 23865-23874.

(34) Anouti, M.; Timperman, L.; El Hilali, M.; Boisset, A.; Galiano, H. Sulfonium bis(trifluorosulfonimide) plastic crystal ionic liquid as an electrolyte at elevated temperature for high-energy supercapacitors. Journal of Physical Chemistry C 2012, 116, 9412-9418.

(35) Coadou, E.; Timperman, L.; Jacquemin, J.; Galiano, H.; Hardacre, C.; Anouti, M. Comparative study on performances of trimethyl-sulfonium and trimethyl-ammonium based ionic liquids in molecular solvents as electrolyte for electrochemical double layer capacitors. Journal of Physical Chemistry C 2013, 117, 10315-10325.

(36) Coadou, E.; Goodrich, P.; Neale, A. R.; Timperman, L.; Hardacre, C.; Jacquemin, J.; Anouti, M. Synthesis and Thermophysical Properties of Ether-Functionalized Sulfonium Ionic Liquids as Potential Electrolytes for Electrochemical Applications. ChemPhysChem 2016, 17, 3992-4002.

(37) Orita, A.; Kamijima, K.; Yoshida, M.; Yang, L. Application of sulfonium-, thiophenium-, and thioxonium-based salts as electric double-layer capacitor electrolytes. Journal of Power Sources 2010, 195, 6970-6976.
(38) Tsunashima, K.; Sugiya, M. Physical and electrochemical properties of lowviscosity phosphonium ionic liquids as potential electrolytes. Electrochemistry Communications 2007, 9, 2353-2358.

(39) Chaban, V. V.; Voroshylova, I. V.; Kalugin, O. N.; Prezhdo, O. V. Acetonitrile Boosts Conductivity of Imidazolium Ionic Liquids. The Journal of Physical Chemistry B 2012, 116, 7719-7727.

(40) Chaban, V. V.; Prezhdo, O. V. How Toxic Are Ionic Liquid/Acetonitrile Mixtures? The Journal of Physical Chemistry Letters 2011, 2, 2499-2503.

(41) Lewandowski, A.; Olejniczak, A.; Galinski, M.; Stepniak, I. Performance of carbon-carbon supercapacitors based on organic, aqueous and ionic liquid electrolytes. Journal of Power Sources 2010, 195, 5814-5819.

(42) Ruiz, V.; Huynh, T.; Sivakkumar, S. R.; Pandolfo, A. G. Ionic liquid-solvent mixtures as supercapacitor electrolytes for extreme temperature operation. RSC Advances 2012, 2, 5591.

(43) Mourad, E.; Coustan, L.; Lannelongue, P.; Zigah, D.; Mehdi, A.; Vioux, A.; Freunberger, S. A.; Favier, F.; Fontaine, O. Biredox ionic liquids with solid-like redox density in the liquid state for high-energy supercapacitors. Nature Materials 2017, 16, 446-453.

(44) Huo, Y.; Xia, S.; Ma, P. Densities of Ionic Liquids, 1-Butyl-3-methylimidazolium Hexafluorophosphate and 1-Butyl-3methylimidazolium Tetrafluoroborate, with Benzene, Acetonitrile, and 1Propanol at $\mathrm{T}=(293.15$ to 343.15$) \mathrm{K}$. Jour nal of Chemical $\mathcal{E}$ Engineering Data 2007, 52, 2077-2082.

(45) Wang, J.; Tian, Y.; Zhao, Y.; Zhuo, K. A volumetric and viscosity study for the mixtures of 1-n-butyl-3methylimidazolium tetrafluoroborate ionic liquid with acetonitrile, 
dichloromethane, 2-butanone and $\mathrm{N}, \mathrm{N}$ ? dimethylformamide. Green Chemistry 2003, 5, $618-622$.

(46) Bešter-Rogač, M.; Stoppa, A.; Hunger, J.; Hefter, G.; Buchner, R. Association of ionic liquids in solution: a combined dielectric and conductivity study of $[\mathrm{bmim}][\mathrm{Cl}]$ in water and in acetonitrile. Physical Chemistry Chemical Physics 2011, 13, $17588-17598$.

(47) Chaban, V. V.; Andreeva, N. A. Solvation of the morpholinium cation in acetonitrile. Effect of an anion. Journal of Molecular Modeling 2016,

(48) Thompson, M. W.; Matsumoto, R.; Sacci, R. L.; Sanders, N. C.; Cummings, P. T. Scalable Screening of Soft Matter: A Case Study of Mixtures of Ionic Liquids and Organic Solvents. The Journal of Physical Chemistry B 2019, 123, 1340-1347.

(49) Sampaio, A. M.; Fileti, E. E.; Siqueira, L. J. Atomistic study of the physical properties of sulfoniumbased ionic liquids as electrolyte for supercapacitors. Journal of Molecular Liquids 2019, 296, 112065.

(50) Neto, A. J. P.; Fileti, E. E. Differential Capacitance and Energetics of the Electrical Double Layer of Graphene Oxide Supercapacitors: Impact of the Oxidation Degree. The Journal of Physical Chemistry C 2018, 122, 21824-21832.

(51) Neto, A.; Fileti, E. An atomistic physicochemical description of acetonitrile/tricyanomethanide based electrolytes. Journal of Molecular Liquids 2019, 292, 111439.

(52) Merlet, C.; Rotenberg, B.; Madden, P. A.; Taberna, P.-1.; Simon, P.; Gogotsi, Y.; Salanne, M. On the molecular origin of supercapacitance in nanoporous carbon electrodes. Nature Materials 2012, 11, 306310.
(53) Merlet, C.; Péan, C.; Rotenberg, B.; Madden, P. A.; Simon, P.; Salanne, M. Simulating Supercapacitors: Can We Model Electrodes As Constant Charge Surfaces? The Journal of Physical Chemistry Letters 2013, 4, 264-268.

(54) Noh, C.; Jung, Y. Understanding the charging dynamics of an ionic liquid electric double layer capacitor via molecular dynamics simulations. Physical Chemistry Chemical Physics 2019, 21, 6790-6800.

(55) Pereira, G. F. L.; Pereira, R. G.; Salanne, M.; Siqueira, L. J. A. Molecular Dynamics Simulations of EtherModified Phosphonium Ionic Liquid Confined in between Planar and Porous Graphene Electrode Models. The Journal of Physical Chemistry C 2019, 123, 1081610825.

(56) Péan, C.; Merlet, C.; Rotenberg, B.; Madden, P. A.; Taberna, P.-L.; Daffos, B.; Salanne, M.; Simon, P. On the Dynamics of Charging in Nanoporous CarbonBased Supercapacitors. ACS Nano 2014, 8, 1576-1583.

(57) Pean, C.; Rotenberg, B.; Simon, P.; Salanne, M. Multi-scale modelling of supercapacitors: From molecular simulations to a transmission line model. Journal of Power Sources 2016, 326, 680-685.

(58) Bi, S.; Banda, H.; Chen, M.; Niu, L.; Chen, M.; Wu, T.; Wang, J.; Wang, R.; Feng, J.; Chen, T.; Dincă, M.; Kornyshev, A. A.; Feng, G. Molecular understanding of charge storage and charging dynamics in supercapacitors with MOF electrodes and ionic liquid electrolytes. Nature Materials 2020,

(59) Martinez, L.; Andrade, R.; Birgin, E. G.; Martínez, J. M. PACKMOL: A package for building initial configurations for molecular dynamics simulations. Journal of Computational Chemistry 2009, 30, 2157-2164. 
(60) Bhargava, B. L.; Balasubramanian, S. Refined potential model for atomistic simulations of ionic liquid [BMIM][PF6]. The Journal of Chemical Physics 2007, 127, 114510.

(61) Kohagen, M.; Brehm, M.; Thar, J.; Zhao, W.; Müller-Plathe, F.; Kirchner, B. Performance of Quantum Chemically Derived Charges and Persistence of Ion Cages in Ionic Liquids. A Molecular Dynamics Simulations Study of 1- n -Butyl3-methylimidazolium Bromide. The Journal of Physical Chemistry B 2011, 115, 693702.

(62) Zhao, W.; Eslami, H.; Cavalcanti, W. L.; Müller-Plathe, F. A Refined AllAtom Model for the Ionic Liquid 1- $n$-Butyl 3-Methylimidazolium bis(Trifluoromethylsulfonyl)imide [bmim][Tf 2 N]. Zeitschrift für Physikalische Chemie 2007, 221, 1647-1662.

(63) Roy, D.; Maroncelli, M. An Improved Four-Site Ionic Liquid Model. The Journal of Physical Chemistry B 2010, 114, 12629-12631.

(64) Bowron, D. T.; D’Agostino, C.; Gladden, L. F.; Hardacre, C.; Holbrey, J. D.; Lagunas, M. C.; McGregor, J.; Mantle, M. D.; Mullan, C. L.; Youngs, T. G. A. Structure and Dynamics of 1-Ethyl-3methylimidazolium Acetate via Molecular Dynamics and Neutron Diffraction. The Journal of Physical Chemistry B 2010, 114, 7760-7768.

(65) Chaban, V. V.; Voroshylova, I. V.; Kalugin, O. N. A new force field model for the simulation of transport properties of imidazolium-based ionic liquids. Physical Chemistry Chemical Physics 2011, 13, $7910-7920$.

(66) Breneman, C. M.; Wiberg, K. B. Determining atom-centered monopoles from molecular electrostatic potentials. The need for high sampling density in formamide conformational analysis. Jour- nal of Computational Chemistry 1990, 11, 361-373.

(67) Frisch, M. J. et al. Gaussian 09. Gaussian, Inc. Wallingford CT 2009,

(68) Kaminski, G. A.; Friesner, R. A.; TiradoRives, J.; Jorgensen, W. L. Evaluation and reparametrization of the OPLS-AA force field for proteins via comparison with accurate quantum chemical calculations on peptides. Journal of Physical Chemistry B 2001, 105, 6474-6487.

(69) Jorgensen, W. L.; Maxwell, D. S.; TiradoRives, J. Development and testing of the OPLS all-atom force field on conformational energetics and properties of organic liquids. Journal of the American Chemical Society 1996, 118, 11225-11236.

(70) Figueiredo, P. H.; Siqueira, L. J. a.; Ribeiro, M. C. C. The equilibrium structure of lithium salt solutions in etherfunctionalized ammonium ionic liquids. Journal of Physical Chemistry B 2012, 116, 12319-12324.

(71) Morganti, J. D.; Hoher, K.; Ribeiro, M. C.; Ando, R. A.; Siqueira, L. J. Molecular dynamics simulations of acidic gases at interface of quaternary ammonium ionic liquids. Journal of Physical Chemistry C 2014, 118, 22012-22020.

(72) Bussi, G.; Donadio, D.; Parrinello, M. Canonical sampling through velocity rescaling. The Journal of Chemical Physics 2007, 126, 14101.

(73) Parrinello, M.; Rahman, A. Polymorphic transitions in single crystals: A new molecular dynamics method. Journal of Applied Physics 1981, 52, 7182-7190.

(74) Darden, T.; York, D.; Pedersen, L. Particle mesh Ewald: An N.log(N) method for Ewald sums in large systems. The Journal of Chemical Physics 1993, 98, 10089-10092. 
(75) Hess, B.; Bekker, H.; Berendsen, H. J. C.; Fraaije, J. G. E. M. LINCS: A linear constraint solver for molecular simulations. Journal of Computational Chemistry 1997, 18, 1463-1472.

(76) Brehm, M.; Kirchner, B. TRAVIS - A free analyzer and visualizer for monte carlo and molecular dynamics trajectories. Journal of Chemical Information and Modeling 2011, 51, 2007-2023.

(77) Van Der Spoel, D.; Lindahl, E.; Hess, B.; Groenhof, G.; Mark, A. E.; Berendsen, H. J. C. GROMACS: Fast, flexible, and free. Journal of Computational Chemistry 2005, 26, 1701-1718.

(78) Berendsen, H. J.; van der Spoel, D.; van Drunen, R. GROMACS: A messagepassing parallel molecular dynamics implementation. Computer Physics Communications 1995, 91, 43-56.

(79) Lindahl, E.; Hess, B.; van der Spoel, D. GROMACS 3.0: A package for molecular simulation and trajectory analysis. 2001.

(80) Hess, B.; Kutzner, C.; Van Der Spoel, D.; Lindahl, E. GROMACS 4: Algorithms for highly efficient, load-balanced, and scalable molecular simulation. Journal of Chemical Theory and Computation 2008, 4, 435-447.

(81) Plimpton, S. Fast Parallel Algorithms for Short-Range Molecular Dynamics. Journal of Computational Physics 1995, 117, 119.

(82) Wang, Z.; Yang, Y.; Olmsted, D. L.; Asta, M.; Laird, B. B. Evaluation of the constant potential method in simulating electric double-layer capacitors. The Journal of Chemical Physics 2014, 141, 184102.

(83) Reed, S. K.; Lanning, O. J.; Madden, P. A. Electrochemical interface between an ionic liquid and a model metallic electrode. The Journal of Chemical Physics 2007, 126, 084704.
(84) Allen, M. P.; Tildesley, D. J. Oxford University Press; Oxford University Press: New York, 1987.

(85) Hansen, J. P.; McDonald, I. R. Theory of Simple Liquids; Elsevier, 2006.

(86) Wang, Z.; Olmsted, D. L.; Asta, M.; Laird, B. B. Electric potential calculation in molecular simulation of electric double layer capacitors. Journal of Physics: Condensed Matter 2016, 28, 464006.

(87) Shim, Y.; Kim, H. J.; Jung, Y. Graphenebased supercapacitors in the parallelplate electrode configuration: Ionic liquidsversus organic electrolytes. Faraday Discuss. 2012, 154, 249-263.

(88) Siqueira, L. J.; Urahata, S. M.; Ribeiro, M. C. Molecular dynamics simulation of molten sodium chlorate. Journal of Chemical Physics 2003, 119, 8002-8012.

(89) Siqueira, L. J. A.; Ribeiro, M. C. C. Molecular dynamics simulation of the ionic liquid N-Ethyl-N,N-dimethylN-(2-methoxyethyl)ammonium bis(trifluoromethanesulfonyl)imide. Journal of Physical Chemistry B 2007, 111, 11776-11785.

(90) Canongia Lopes, J. N.; Pádua, A. A. Molecular force field for ionic liquids III: Imidazolium, pyridinium, and phosphonium cations; chloride, bromide, and dicyanamide anions. Journal of Physical Chemistry B 2006, 110, 19586-19592.

(91) Shimizu, K.; Almantariotis, D.; Gomes, M. F. C.; Pádua, A. A. H.; Canongia Lopes, J. N. Molecular Force Field for Ionic Liquids V: Hydroxyethylimidazolium, Dimethoxy-2- Methylimidazolium, and Fluoroalkylimidazolium Cations and Bis(Fluorosulfonyl)Amide, Perfluoroalkanesulfonylamide, and Fluoroalkylfluorophosphate Anions. The Journal of Physical Chemistry B 2010, 114, 3592-3600. 
(92) Klähn, M.; Seduraman, A.; Wu, P. A model for self-diffusion of guanidiniumbased ionic liquids: A molecular simulation study. Journal of Physical Chemistry B 2008, 112, 13849-13861.

(93) Bernardes, C. E. S.; Minas da Piedade, M. E.; Canongia Lopes, J. N. The Structure of Aqueous Solutions of a Hydrophilic Ionic Liquid: The Full Concentration Range of 1-Ethyl-3methylimidazolium Ethylsulfate and Water. The Journal of Physical Chemistry $B$ 2011, 115, 2067-2074.

(94) Anouti, M.; Jacquemin, J.; Lemordant, D. Volumetric Properties, Viscosities, and Isobaric Heat Capacities of Imidazolium Octanoate Protic Ionic Liquid in Molecular Solvents. Journal of Chemical E Engineering Data 2010, 55, 5719-5728.

(95) Nikitin, A. M.; Lyubartsev, A. P. New sixsite acetonitrile model for simulations of liquid acetonitrile and its aqueous mixtures. Journal of Computational Chemistry 2007, 28, 2020-2026.

(96) Stoppa, A.; Hunger, J.; Buchner, R. Conductivities of Binary Mixtures of Ionic Liquids with Polar Solvents †. Journal of Chemical E Engineering Data 2009, 54, 472-479.

(97) Li, W.; Zhang, Z.; Han, B.; Hu, S.; Xie, Y.; Yang, G. Effect of Water and Organic Solvents on the Ionic Dissociation of Ionic Liquids. The Journal of Physical Chemistry B 2007, 111, 6452-6456.

(98) Borodin, O. Polarizable Force Field Development and Molecular Dynamics Simulations of Ionic Liquids. The Journal of Physical Chemistry B 2009, 113, 1146311478.

(99) Siqueira, L. J. A.; Ribeiro, M. C. C. Charge ordering and intermediate range order in ammonium ionic liquids. The Journal of Chemical Physics 2011, 135, 204506.
(100) Vatamanu, J.; Vatamanu, M.; Borodin, O.; Bedrov, D. A comparative study of room temperature ionic liquids and their organic solvent mixtures near charged electrodes. Journal of Physics: Condensed Matter 2016, 28, 464002.

(101) Merlet, C.; Salanne, M.; Rotenberg, B.; Madden, P. A. Influence of solvation on the structural and capacitive properties of electrical double layer capacitors. Electrochimica Acta 2013, 101, 262-271.

(102) Pean, C.; Rotenberg, B.; Simon, P.; Salanne, M. Understanding the different (dis)charging steps of supercapacitors: influence of potential and solvation. Electrochimica Acta 2016, 206, 504-512. 


\section{Graphical TOC Entry}

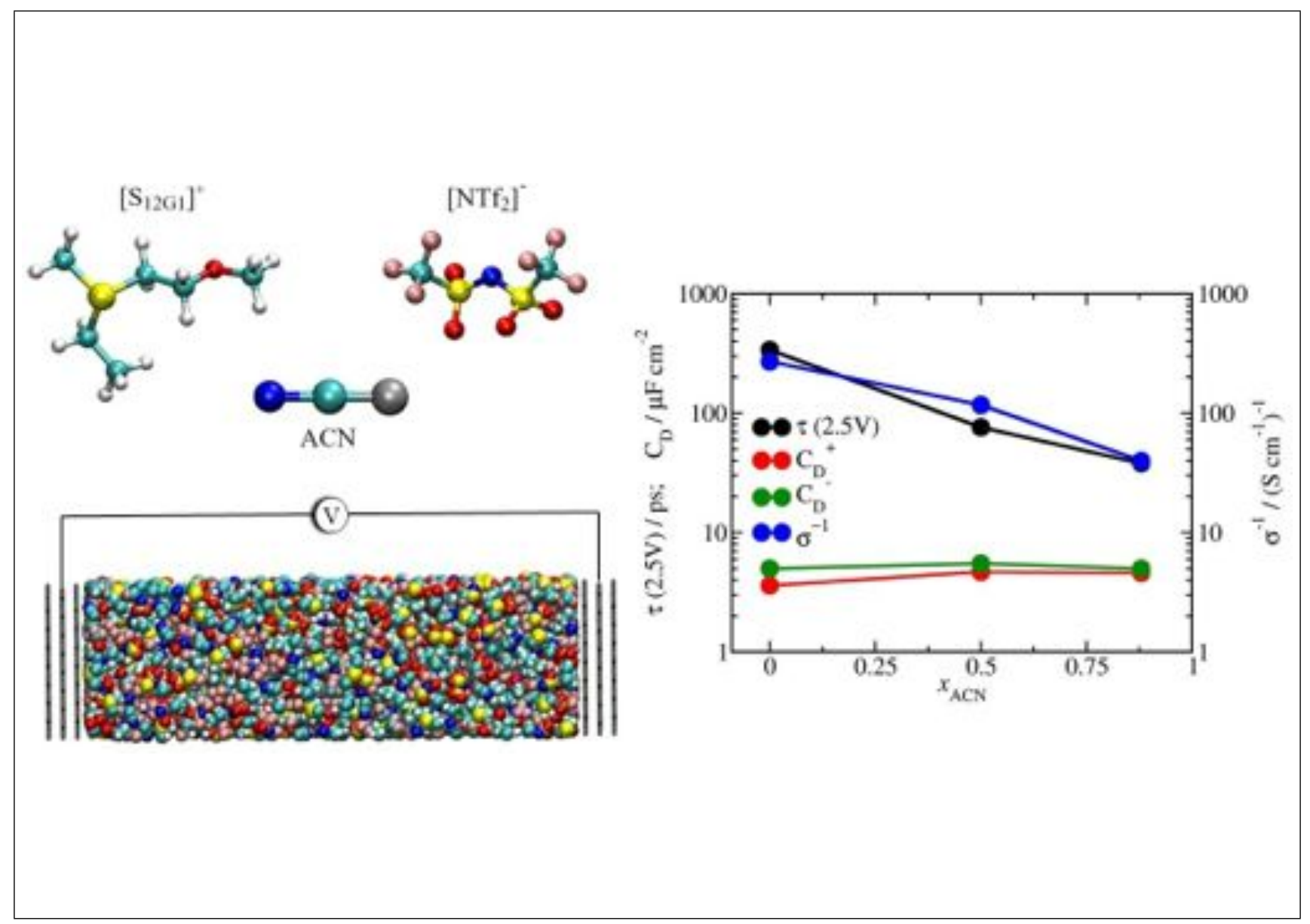

